\title{
Proposal for Cryogenic Deburring Equipment's Design and Thermal Insulation
}

\author{
Rares Campean ${ }^{1}$ and Liana Hancu, ${ }^{2, *}$ \\ ${ }^{1}$ Technical University of Cluj Napoca, Department of Manufacturing Engineering, B-dul Muncii, \\ 103-105 Cluj Napoca, RO 400641 \\ ${ }^{2}$ Technical University of Cluj Napoca, Department of Manufacturing Engineering, B-dul Muncii, \\ 103-105 Cluj Napoca, RO 400641
}

\begin{abstract}
In the paper are presented elements of the deburring technology of rubber or plastic parts in cryogenic conditions. There is a proposal for deburring equipment that follows: simplicity in use, increased production capacity and reduced consumption of liquid nitrogen. The heat transfer through the insulating layer is calculated using several types of thermal insulation: perlite powder, spray-on polyurethane foam and aerogel blanket. The obtained results are used for the design of a cryogenic deburring equipment where the thermal transfer is minimal.
\end{abstract}

\section{Introduction}

The use of plastics and composites in the current era is due to their important advantages such as superior characteristics of corrosion resistance, ease of processing or low density and weight. They are successfully replacing metallic materials whose processing is difficult and expensive. Generally, rubber and plastic parts are obtained in a mould by pressing or injection. The burrs (internal or external) are usually formed in the parting plane of the mould so the way the mould is designed is very important for minimizing the burrs and as much is possible the inner ones to be excluded. The goal of the deburring process is to clean the parts from the burrs that have appeared on their surface during the manufacturing process. The use of cryogenic deburring technology leads to clean the interior and exterior burrs of the parts, in a much shorter time and with a higher quality than by using other methods. Cryogenic temperatures range from absolute zero, $0 \mathrm{~K}$ to $123 \mathrm{~K}$ and the main chemical elements used in the cryogenic field are: liquid nitrogen, liquid oxygen, liquid argon, liquid neon, hydrogen and helium (3He and 4He) [1]. In the technical field, cryogenics is used in several manufacturing processes, for example turning, drilling, stamping, deburring, or assembling [2]. The cryogenic deburring technology is based on the cooling of the material until it reaches the vitrification point $\mathrm{T}_{\mathrm{v}}$, where it is losing its elasticity. The cooled areas become brittle, being sensitive to shocks and by correctly setting the deburring time and temperature, the breakage will be obtained only for the burrs and not for the part.

*Corresponding author: Liana.Hancu@tcm.utcluj.ro 
For cryogenic deburring, the parts are inserted into a chamber that is cooled by the cryogenic agent. The enclosure and the drive elements from inside must ensure, after cooling under the vitrification point of the material, the collision of the pieces between them, or with other bodies, thus ensuring the burr detachment. The cryogenic deburring equipments have several elements, necessary for the thermo-mechanical process. These include:

- the cryogenic liquid cooling system;

- the thermal insulation system of the chamber where the process is performed;

- the system for driving and colliding parts;

- control, adjustment and measurement equipment.

\section{Design and calculation for a thermal insulation}

\subsection{Design principles}

When designing an installation for cryogenic deburring, it is necessary to pay attention to elements such as the thermal insulation and the thickness of the insulating layer, the shape and positioning of the enclosure, or the way the parts are driven.

The correct choice of the material from which the interior and exterior enclosure of the cryogenic chamber is made is essential for a proper operation. For the construction of cryogenic enclosures steel or reinforced polymeric materials are used. Alloy steels, with $1.5 \% \ldots 9 \%$ nickel are those that have the best characteristics in the cryogenic conditions. In this type of steel, as we increase the percentage of $\mathrm{Ni}$, the lower the temperature at which it can be used. At a concentration of $3.5 \%$ nickel the range of use will be up to $170 \mathrm{~K}$, and at a concentration of $9 \% \mathrm{Ni}$ it will be possible to use up to $77 \mathrm{~K}$ [3].

To reduce the use of cryogenic fluid and to increase the efficiency of the machine, more attention will be paid to the insulation of the machine. The most commonly used cryogenic fluid for various technologies is liquid nitrogen with a boiling point of $77 \mathrm{~K}$.

As an important design principle it is to optimize the thickness of the insulation and the correct choice of the material for it. That will determine both the nitrogen consumption necessary for the cryogenic deburring process, as well as the size and weight of the cryogenic enclosure.

For the equipment designed and presented in the paper, three types of insulators were chosen (Aerogel Blanket, Spray-On Polyurethane Foam, Perlite Powder) [4] for which the liquid nitrogen flow rate is calculated according to the wall thickness.

\subsection{Thermal insulation}

The thermal insulation design involves choosing the insulating material and the size of the layer between the inner and the outer enclosures of the chamber in which it will be inserted. In the paper the calculation of the liquid nitrogen flow for the three types of thermal insulation for a variable insulating layer thickness are presented. After comparing the results, the thickness and type of thermal insulation that is recommended are determined.

Table 1. The thermal conductivity coefficient of the insulators [4]

\begin{tabular}{|l|c|c|c|}
\hline Types of insulation & Aerogel blanket & $\begin{array}{c}\text { Spray-on } \\
\text { polyurethane foam }\end{array}$ & Perlite powder \\
\hline $\begin{array}{l}\text { Thermal conductivity, } \\
\mathbf{K}_{\mathrm{pp}}[\mathbf{W} / \mathbf{m} \cdot \mathbf{K}]\end{array}$ & 0.011 & 0.022 & 0.035 \\
\hline
\end{tabular}


Nitrogen, the cryogenic fluid used by the authors, it has a density $(\rho)$ of $0.808 \mathrm{~kg} / \mathrm{dm}^{3}$ and latent heat of vaporization $(\lambda)$ of $199.22 \cdot 103 \mathrm{~J} / \mathrm{kg}$ [5]. The temperature in the interior enclosure $\left(\mathrm{T}_{\mathrm{int}}\right)$ is given by nitrogen vapours and has a value of $143 \mathrm{~K}$. The Stefan Boltzmann constant is represented by $\sigma\left(=5.670 \cdot 10^{-8} \mathrm{~W} \cdot \mathrm{m}^{-2} \cdot \mathrm{K}{ }^{-4}\right)$ and the thermal conductivity coefficient $\left(\mathrm{K}_{\mathrm{oi}}\right)$ of the stainless steel is $14.4 \mathrm{~W} / \mathrm{m} \cdot \mathrm{K}$ [3]. The areas $\left(\mathrm{A}_{\mathrm{ext}} ; \mathrm{A}_{\mathrm{int}}\right.$; $\left.A_{b r}\right)$ are selected from the data of the designed installation (presented in 3.1) and represent the area of the outer surface of the cryogenic chamber, the interior area and the area of the metal bridge between the walls. The thickness of the insulating layer $(\mathrm{S})$ varies from $10 \mathrm{~mm}$ to $100 \mathrm{~mm}$. With relation (1) the liquid nitrogen flow necessary to bring the chamber to the working temperature was calculated.

$$
D_{V}=\frac{60}{\rho \times \lambda} \times\left\{\left[2.7 \times 10^{-8} \times A_{\text {ext }}+\sigma \times E \times A_{\text {int }} \times\left(T_{\text {ext }}^{4}-T_{\text {int }}^{4}\right)\right]+\frac{A_{\text {ext }} \times \int_{T_{\text {int }}}^{T_{\text {ext }}} K_{p p p} d T+A_{b r} \times \int_{T_{i n t}}^{T_{\text {ext }}} K_{\text {oi }} d T}{S}\right\}
$$

\subsubsection{Aerogel blanket}

Table 2. Liquid nitrogen flow for different thicknesses of the insulating layer of aerogel blanket

\begin{tabular}{|l|l|l|l|l|l|l|l|l|l|l|}
\hline $\mathbf{S} \quad[\mathbf{m m}]$ & 10 & 20 & 30 & 40 & 50 & 60 & 70 & 80 & 90 & 100 \\
\hline $\mathbf{D}_{\mathbf{v}}[\mathbf{I} / \mathbf{m i n}]$ & 3.463 & 1.811 & 1.260 & 0.985 & 0.820 & 0.710 & 0.631 & 0.572 & 0.526 & 0.489 \\
\hline
\end{tabular}

\subsubsection{Spray-on polyurethane foam}

Table 3. Liquid nitrogen flow for different thicknesses of the insulating layer of polyurethane foam

\begin{tabular}{|c|c|c|c|c|c|c|c|c|c|c|}
\hline $\mathbf{S} \quad[\mathrm{mm}]$ & 10 & 20 & 30 & 40 & 50 & 60 & 70 & 80 & 90 & 100 \\
\hline$D_{v}[1 / \mathrm{min}]$ & 3.698 & 1.929 & 1.339 & 1.044 & 0.867 & 0.749 & 0.665 & 0.601 & 0.552 & 0.513 \\
\hline
\end{tabular}

\subsubsection{Perlite powder}

Table 4. Liquid nitrogen flow for different thicknesses of the insulating layer of perlite powder

\begin{tabular}{|c|c|c|c|c|c|c|c|c|c|c|}
\hline $\mathbf{S} \quad[\mathbf{m m}]$ & 10 & 20 & 30 & 40 & 50 & 60 & 70 & 80 & 90 & 100 \\
\hline$D_{\mathrm{v}}[\mathrm{l} / \mathrm{min}]$ & 3.934 & 2.047 & 1.417 & 1.103 & 0.914 & 0.788 & 0.698 & 0.631 & 0.578 & 0.537 \\
\hline
\end{tabular}

\subsubsection{Comparative results}

The diagram shown in fig. 1 illustrates the values of the nitrogen flow according to the thickness of the insulating wall, for the three types of insulation proposed. The created curve has a decreasing tendency and is repeated in all isolations. For perlite powder it can be seen in the first part of the graph that the nitrogen flow decreases considerably from $3.934 \mathrm{l} / \mathrm{min}(10 \mathrm{~mm})$ to $1.417 \mathrm{l} / \mathrm{min}(30 \mathrm{~mm})$, and then a slower decrease begins to 0.788 $(60 \mathrm{~mm})$. For the proposed equipment, this is the dimension of the insulating layer $(60 \mathrm{~mm})$ that will be considered for thermal insulation in powder form. 


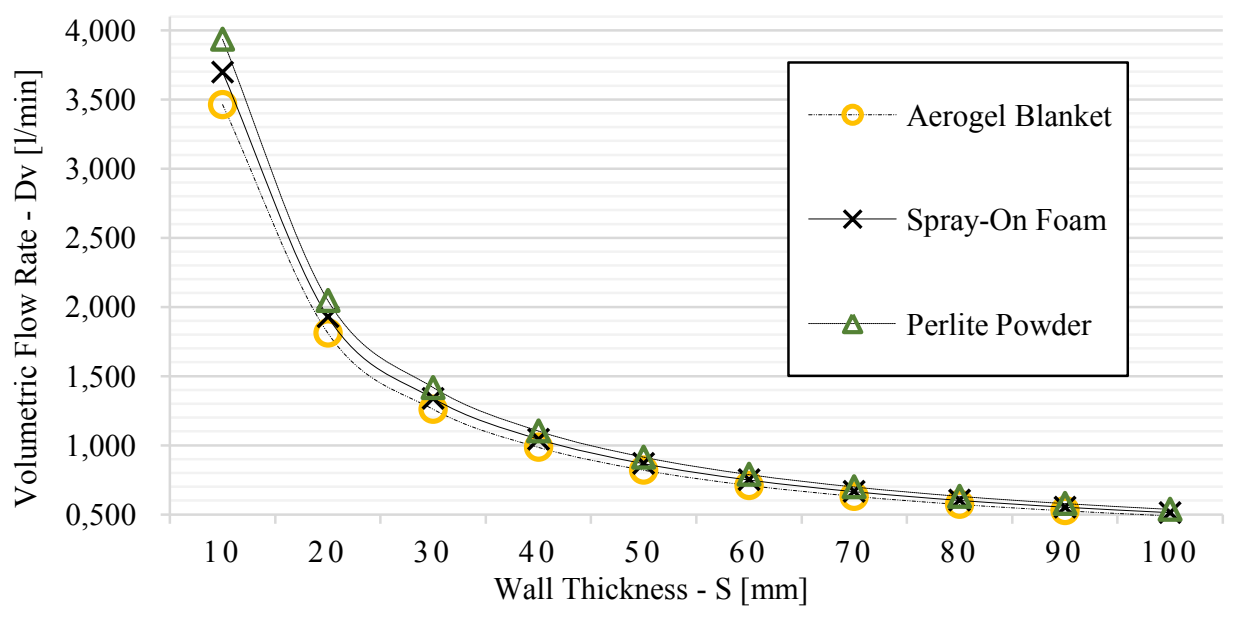

Fig. 1. Comparison diagram of nitrogen flow for the three types of insulators according to the wall thickness

On the last segment of the graph the decrease of the slope is tempered and the differences between the values of the nitrogen flow are minim. It can be observed that for a thickness of $10 \mathrm{~mm}$ the differences between the three insulators are relatively large, and gradually as the insulation layer thickness increases the values begin to be very much alike.

\section{Equipment for cryogenic deburring}

\subsection{Operation}
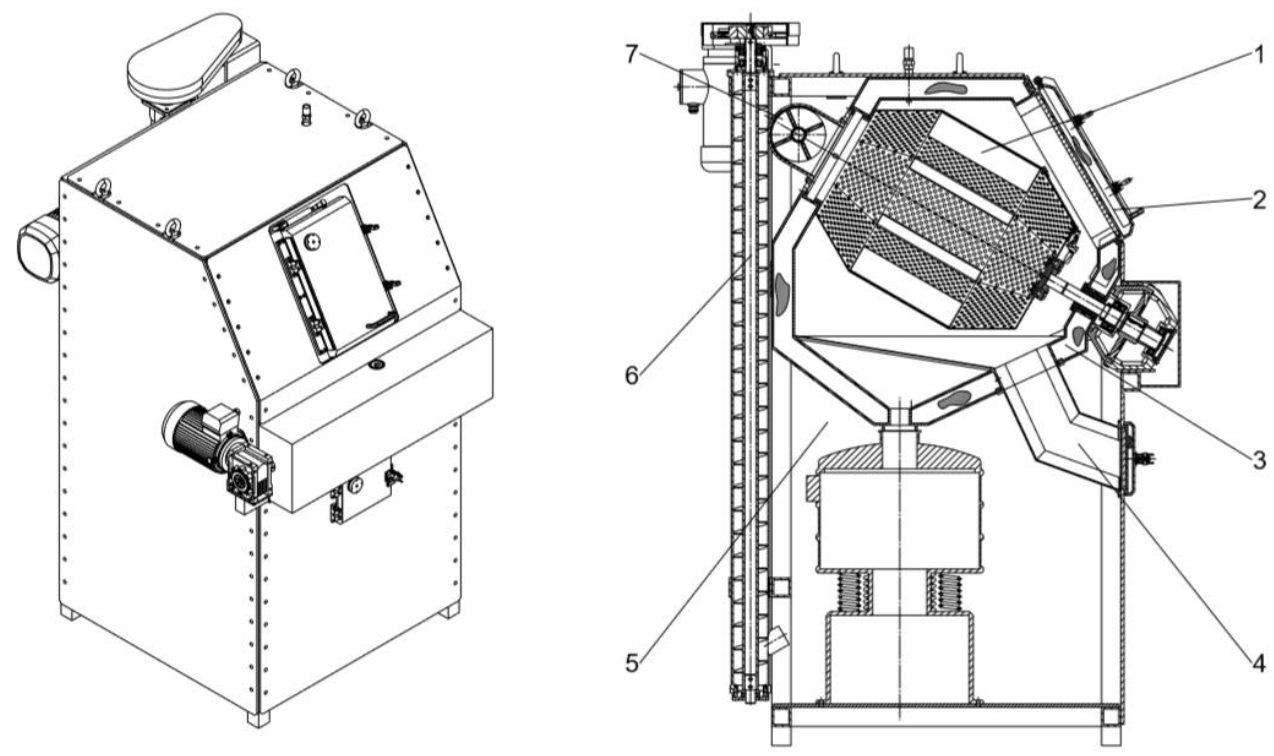

Fig. 2. Cryogenic deburring machine 
The proposed cryogenic deburring equipment, shown in fig. 2 is divided into 7 main subassemblies. The rotary drum and the drive system (1) receive the rotation from an engine with the power of $0.75 \mathrm{~kW}$ to which a screwdriver is attached [6]. Between the spindle that is coming out of the gearbox and the enclosure is a conical gear. The main engine speed is reduced from $1400 \mathrm{rpm}$ to $50 \mathrm{rpm}$. The drum has an octagonal shape in section and is provided with a folding lid on one of the faces, where the pieces and the bumping granules are inserted inside the rotary drum. The lid is provided with a toggle clamp.

The drum is placed inside the thermally insulated chamber (3). The thickness of the insulating wall is $70 \mathrm{~mm}$, of which $60 \mathrm{~mm}$ is an insulating layer made of perlite powder and $5 \mathrm{~mm}$ is the thickness of the steel wall $(10 \mathrm{~mm}$ for both walls). The upper enclosure is provided with an opening for the main door of the installation (2). Inside the main door is introduced perlite powder to insulate thermally, and on the outside is provided with two toggle clamps that ensure the sealed door. In the lower enclosure there is a perforated plate that allows the granules and burrs to pass and directs the pieces to the evacuating system (4). This subassembly consists of a tube and an exhaust door. At the bottom of the lower enclosure is placed an orifice that connects to the cryogenic cooled enclosure and a vibrating sorting machine from SWECO [7]. This has the role of sorting the granules of polycarbonate from the burr and redirecting them to the vertical conveyor (6). It transports them to the propeller drive system (7). The conveyor receives the rotation from a $1.5 \mathrm{~kW}$ motor through a belt transmission with a ratio of $1: 2$ [6].

The granular bombardment system has an axially perforated propeller on which the pliers are inserted. The propeller is caught by a flange of a moving shaft, which receives rotation from a $3 \mathrm{~kW}$ engine and can reach up to $6000 \mathrm{rpm}$ [6].

All the subassemblies are fastened by a metal frame (5) made of laminated steel bars with square section, welded together. Outside the machine is covered in painted aluminium plates, with a thickness of $4 \mathrm{~mm}$.

\subsection{Technical data}

Table 5. Technical data of the designed deburring machine

\begin{tabular}{|l|l|}
\hline Insulation & Pearlite powder, $60 \mathrm{~mm}$ \\
\hline Enclosure material & X2CrNi18-9 \\
\hline Batch volume & 451 \\
\hline Drum speed & $5-50 \mathrm{rpm}$ \\
\hline Centrifuge speed & $1000-6000 \mathrm{rpm}$ \\
\hline Conveyor speed & $750 \mathrm{rpm}$ \\
\hline Bump granules & $0.5-1.5 \mathrm{~mm}$ polycarbonate \\
\hline Weight & $1300 \mathrm{~kg}$ \\
\hline Dimensions machine & $1100 \mathrm{~mm} \mathrm{~L} \mathrm{x} 1900 \mathrm{~mm} \mathrm{I} \mathrm{x} 1300 \mathrm{~mm} \mathrm{~A}$ \\
\hline Required power & $6 \mathrm{~kW}$ \\
\hline Electrical Service & $3 \mathrm{Ph}, 460 \mathrm{Volts}, 60 \mathrm{~A}, 60 \mathrm{~Hz}$ \\
\hline Refrigerant & $\mathrm{LN} 2.5 \mathrm{bar}$ \\
\hline Working temperature & $-130^{\circ} \mathrm{C}$ \\
\hline Separator & $\mathrm{SWECO}, 610 \mathrm{~mm}$ \\
\hline
\end{tabular}




\subsection{Operating instructions}

For loading the chamber, it is necessary to open the main door of the exterior enclosure and then lift the lid provided on one of the faces of the drum and insert the parts. Position the rotary drum cover by fastening the clamp and then close the main door. Liquid nitrogen is vaporized until a constant temperature of $144 \pm 5 \mathrm{~K}$ is obtained inside. The cycle starts after setting the rotation speed of the drum and the rate of granulation propulsion. The deburring time is set according to the thickness of the part and of the burr so that the break can be obtained only for the burr and not for the component [8]. At the end of the process the two main doors are opened and then the drum will perform a $180^{\circ}$ rotation, thus releasing the internal parts on the perforated plate. The parts reach the bottom tube and are removed from the machine by opening the lower door. Granules have a separate circuit, they must be inserted only once in the machine and enter the cycle consisting of a bumping system, separator and vertical conveyor.

\section{Conclusions}

In order to reach the final shape and dimensions of the equipment for cryogenic deburring, it is necessary to pay more attention to the type of the insulating material and the thickness of the walls. Following the calculations, it was concluded that the thickness of the thermal insulation layer should be $60 \mathrm{~mm}$. Above this value, the calculated liquid nitrogen flow rate will not decrease significantly.

The goal is both to maintain the liquid nitrogen flow rate at a reasonable level $\left(D_{v}=\right.$ $0.788 \mathrm{l} / \mathrm{min}$ ), as well as to maintain the dimensions and the weight of the equipment at a reduced value.

The type of insulation chosen is perlite powder. Despite the fact that it has the highest values of nitrogen flow, compared to polyurethane foam and aerogel blanket, the differences between them are not significant. Thermal insulation with perlite powder has several functional advantages compared to the other types presented.

The most important advantage of perlite powder is its ease of use. The powder can be removed from the special hole created on the outer wall of each room relatively easily. The complex geometry of the drum where the process takes place has the role of reducing the space to be cooled as efficiently as possible as this decreases the flow of liquid nitrogen that is required.

\section{References}

1. K. D. Timmerhaus, T. M. Flynn, Cryogenic Process Engineering (1989)

2. I. Tapalaga, P. Berce, H. Iancau, Criogenia in constructii de masini (1988)

3. C. Stamatescu, M. Peculea, V. Radcenco, Criogenia Tehnica (1982)

4. F. J. Edeskuty, W. F. Stewart, Safety in the Handling of Cryogenic Fluids (1996)

5. J. E. Fesmire, Standardization in cryogenic insulation systems testing and performance data Int. Cryogenic Eng.Conf. (2014)

6. http://www.powerjacks.com/products/system-components/electric-motors

7. http://www.sweco.com/screener-classic-separator.aspx

8. L Hancu, D.Paunescu, H. Iancau, M. Suciu, Aspects Concerning some Polymeric Composites' Behaviour at Cryogenic Temperatures, DAAAM (2009) 